\title{
Analisis Konsepsi Awal Siswa pada Materi Siklus Air Kelas V SD
}

\author{
Ilma Nasukha*, Sri Estu Winahyu, M. Anas Thohir \\ Universitas Negeri Malang, Jl. Semarang No. 5 Malang, Jawa Timur, Indonesia \\ *Penulis korespondensi, Surel: ilmanaskha@gmail.com
}

Paper received: 6-8-2021; revised: 20-8-2021; accepted: 28-8-2021

\begin{abstract}
This study aims to reveal students' initial conceptions of the water cycle material for class V. The method used in this research is descriptive qualitative. Data collection techniques used by researchers are using questionnaires, interviews and documentation. The instrument used to collect data is the researcher himself. The steps of data analysis used in the study, namely: (1) data reduction, (2) data presentation, and (3) making conclusions. The results of this study, obtained the fact that students' initial conceptions have initial conceptions that are scientifically correct and not scientifically correct.
\end{abstract}

Keywords: conception; beginning; student; water cycle

\begin{abstract}
Abstrak
Penelitian ini bertujuan untuk mengungkap konsepsi awal siswa pada materi siklus air kelas V. metode yang digunakan dalam penelitian ini yaitu kualitatif deskriptif. Teknik pengumpulan data yang digunakan oleh peneliti yaitu menggunakan angket, wawancara dan dokumentasi. Instrumen yang digunakan untuk mengumpulkan data, yaitu peneliti sendiri. Langkah-langkah analisis data yang digunakan dalam penelitian, yaitu: (1) reduksi data, (2) penyajian data, dan (3) membuat kesimpulan. Hasil dari penelitian ini, diperoleh fakta adanya konsepsi awal siswa memiliki konsepsi awal yang sudah benar secara ilmiah dan belum benar secara ilmiah.
\end{abstract}

Kata kunci: konsepsi; awal; siswa; siklus air

\section{Pendahuluan}

Pendidikan merupakan hal yang sangat penting dan selalu diperlukan oleh manusia karena manusia tidak akan lepas dari pendidikan. Sujana \& Jayadinata (2018) mengatakan bahwa "Pendidikan merupakan suatu sistem yang sangat kompleks dan terdiri dari beberapa komponen yang satu sama lain saling memengaruhi". Pada hakikatnya tujuan dari pendidikan yaitu mengarahkan siswa untuk memiliki pengetahuan, keterampilan, serta sikap yang positif untuk digunakan dalam menjalani kehidupan. Maka pendidikan dapat dikatakan berhasil jika siswa mengalami perubahan ke arah yang lebih positif dalam perkembangan pengetahuan, penguasaan keterampilan, dan perubahan sikap positif dalam kehidupannya. Peran penting dari seorang guru sangat diperlukan dalam pendidikan.

Peran Guru dalam pendidikan adalah mengantarkan siswa mencapai ketuntasan belajar dengan memberi bantuan berupa arahan dan bimbingan. Maemunawati \& Alif (2020) menyebutkan peran guru yaitu sebagai pendidik dan pengajar, mediator dan fasilitator, sebagai teladan bagi siswa, sebagai motivator, dan sebagai pembimbing untuk mengarahkan siswa dalam menerima pemahaman konsep yang sedang diajarkan. Guru perlu menggunakan pengetahuan awal tersebut agar dapat membantu siswa dalam mengkonstruksi pengetahuan baru mereka. Dengan diberi perlakuan seperti itu, maka pembelajaran akan lebih mudah diserap, dipahami dan pembelajaran akan terasa lebih bermakna (Maulidya \& Saputri,2016). 
Siswa ketika menerima materi sains yang abstrak dan baru, akan terjadi dua kemungkinan yaitu adanya keseimbangan atau ketidakseimbangan. Menurut Piaget dalam Jahja (2015) agar siswa dapat menerima materi dengan benar, siswa perlu berinteraksi agar dapat memperoleh sebuah skema. Konsepsi awal diperlukan guru untuk membantu persepsi awal siswa dengan informasi baru yang diberikan guru melalui arahan dan bimbingan agar siswa memperoleh pemahaman konsep awal dengan benar. Jika guru sudah mengetahui konsepsi awal yang dimiliki siswa maka guru dapat menuntun siswa dengan cara yang berbeda-beda untuk mendapatkan konsepsi yang benar.

Berdasarkan hasil wawancara yang dilakukan dengan guru kelas V di SDN Gempol 2 pada tanggal 21 Januari 2021, diperoleh bahwa selama pembelajaran berlangsung guru hanya memberi penjelasan singkat mengenai materi yang akan disampaikan karena kekhawatiran guru mengurangi jam pelajaran. Kemudian setelah itu guru memberi tugas kepada siswa untuk mengerjakan tugas yang telah diberikan oleh guru. Sehingga guru hanya menyampaikan materi yang penting saja. Guru juga memaparkan bahwa dalam pembelajaran IPA guru menggunakan waktu yang relatif menghabiskan waktu yang lama apalagi dengan materi yang mengharuskan untuk melakukan percobaan, sedangkan waktu yang dibutuhkan selama pembelajaran sangatlah singkat sehingga guru hanya terbatas dengan penyampaian materi saja.

Selain melakukan wawancara dengan guru, peneliti juga menggali informasi mengenai materi tentang siklus air melalui beberapa pertanyaan spontan yang diajukan oleh peneliti kepada sebagian siswa. Peneliti melakukan wawancara awal dengan lima siswa kelas V. Terdapat tiga pertanyaan yang diajukan peneliti pada saat wawancara. Pertanyaan tersebut meliputi pengetahuan siswa mengenai siklus air, pengetahuan siswa mengenai proses terjadinya hujan, dan pengetahuan siswa mengenai contoh dari siklus air. Hasil dari wawancara tersebut diperoleh jawaban yang beragam dari siswa.

Penelitian yang dilakukan bertujuan untuk mengungkap konsepsi awal siswa terhadap materi siklus air. Menurut Hassanuddin (2020) konsepsi awal sebaiknya digunakan sebagai entry point pada saat pembelajaran agar hal tersebut dapat menjadi pendukung pemahaman siswa dan menjadikan pembelajaran terasa lebih bermakna. Konsepsi awal digunakan guru agar dapat memberikan pembelajaran yang bermakna bagi siswa.

Selain pengambilan data awal di SD lokasi penelitian, peneliti juga melihat data dari penelitian terdahulu yang pernah dilakukan. Penelitian yang dilakukan oleh Qur'aini (2019) yang berjudul "Analisis Konsepsi Siswa Kelas IV Terhadap Konsep Daur Hidup Hewan Pada Muatan Ipa Tema Cita-citaku di SDN Mergosono 1 Malang” menunjukkan bahwa fakta adanya konsepsi yang dimiliki siswa yang sudah benar secara ilmiah dan belum benar secara ilmiah. Penelitian serupa juga dilakukan oleh Ratna (2020) yang berjudul "Analisis Pemahaman Konsep Siswa Pada Pembelajaran IPA di Sekolah Dasar Studi Kasus Pemahaman Konsep Siswa Pada Pembelajaran IPA Pokok Bahasan Siklus Air Kelas V di SDN Jomin Barat IV Kecamatan Kotabaru Kabupaten Karawang" menunjukkan bahwa pemahaman konsep siswa pada pembelajaran IPA masih belum optimal.

Penelitian yang dilakukan untuk menganalisis kemampuan awal siswa dalam penemuan konsep yang terdapat dalam materi siklus air. Dengan mengungkap pengetahuan awal siswa diharapkan seorang guru dapat menggunakannya sebagai acuan untuk meremediasi siswa 
sesuai dengan konsep yang dimiliki tiap siswa agar dapat mencapai tujuan pembelajaran yang diinginkan.

\section{Metode}

Metode yang digunakan dalam penelitian ini menggunakan penelitian kualitatif jenis deskriptif. Penelitian ini dilakukan di SDN Gempol 2 dengan subjek kelas V. Teknik pengumpulan data yang digunakan pada penelitian ini yaitu dengan wawancara, angket, dan dokumentasi. Data yang diperoleh dari angket semi terbuka dianalisis menggunakan rumus persentase kemudian disajikan dalam bentuk tabel dengan rumus sebagai berikut.

$P=\frac{f}{N} \times 100 \%$

Keterangan :

P : Persentase

$\mathrm{f}:$ frekuensi (jawaban responden)

$\mathrm{N}$ : Jumlah Responden

Dari setiap tabel yang diperoleh agar mudah untuk dianalisis, maka digunakan tasiran data dengan perincian sebagai berikut Arikunto dalam Minarso (2017):

$\begin{array}{ll}0 \% & \text { : tidak satupun responden } \\ 1-26 \% & : \text { sebagian kecil responden } \\ 27-49 \% & : \text { hampir setengah responden } \\ 50 \% & : \text { setengahnya } \\ 51-75 \% & \text { : sebagian besar } \\ 76-99 \% & \text { : hampir seluruhnya } \\ 100 \% & \text { : seluruhnya }\end{array}$

\section{Hasil dan Pembahasan}

Konsepsi awal siswa kelas $\mathrm{V}$ tentang materi siklus air didapatkan jawaban yang beragam dari siswa. Pada materi siklus air terdiri dari evaporasi, kondensasi, presipitasi, siklus air pendek, siklus air sedang, dan siklus air panjang. Data konsepsi awal tentang evaporasi pada siklus air didapatkan dari 2 butir soal pertanyaan pada angket, yaitu pada pertanyaan nomor 1 dan 2. Hasil dari jawaban angket siswa dipaparkan pada tabel 1. 
Tabel 1. Konsepsi Awal Siswa pada Evaporasi

\begin{tabular}{|c|c|c|c|c|c|c|}
\hline No & Aspek yang Ditanyakan & Jawaban & Jml & $\%$ & Jawaban Ilmiah & No. Soal \\
\hline \multirow[t]{5}{*}{1} & Pengertian evaporasi & Penguapan & 20 & 62,5 & Penguapan & 1 \\
\hline & & Hujan & 6 & 20 & & \\
\hline & & Pengendapan & 2 & 6,7 & & \\
\hline & & Siklus Air & 2 & 6,7 & & \\
\hline & & $\begin{array}{l}\text {...(jawaban } \\
\text { sendiri) }\end{array}$ & 0 & 0 & & \\
\hline \multirow[t]{6}{*}{2} & Penyebab proses evaporasi & Panas Bumi & 4 & 13 & Panas Matahari & 2 \\
\hline & & Panas & 18 & 60 & & \\
\hline & & Matahari & & & & \\
\hline & & Hujan & 4 & 13 & & \\
\hline & & $\begin{array}{l}\text { Air sungai } \\
\text { dan laut }\end{array}$ & 2 & 6,7 & & \\
\hline & & $\begin{array}{l}\text {...(jawaban } \\
\text { sendiri) }\end{array}$ & 2 & 6,7 & & \\
\hline
\end{tabular}

Hasil tes pada nomor 1 menunjukkan sebagian dari siswa sudah menjawab benar bahwa proses perubahan air menjadi uap air yang terjadi karena adanya pemanasan disebut juga penguapan. Sedangkan pada nomor 2 konsepsi awal siswa tersebut diperoleh hasil hampir separuh dari jumlah keseluruhan siswa memiliki jawaban yang benar secara ilmiah.

Data konsepsi awal tentang kondensasi pada siklus air didapatkan dari 2 butir soal pertanyaan pada angket, yaitu pada pertanyaan nomor 3 dan 4 . Hasil dari jawaban angket siswa dipaparkan pada tabel 2 .

Tabel 2. Konsepsi Awal Siswa tentang Kondensasi

\begin{tabular}{|c|c|c|c|c|c|c|}
\hline No & Aspek yang Ditanyakan & Jawaban & Jml & $\%$ & Jawaban Ilmiah & No. Soal \\
\hline \multirow[t]{5}{*}{1} & Pengertian kondensasi & Evaporasi & 14 & 46,7 & Kondensasi & 3 \\
\hline & & Presipitasi & 0 & 0 & & \\
\hline & & Infiltrasi & 1 & 3 & & \\
\hline & & Kondensasi & 12 & 40 & & \\
\hline & & $\begin{array}{l}\text {...(jawaban } \\
\text { sendiri) }\end{array}$ & 3 & 10 & & \\
\hline \multirow[t]{5}{*}{2} & Proses kondensasi melalui & 1 & 9 & 30 & 4 & 4 \\
\hline & gambar & 2 & 1 & 3,3 & & \\
\hline & & 3 & 2 & 6,7 & & \\
\hline & & 4 & 18 & 60 & & \\
\hline & & $\begin{array}{l}\text {...(jawaban } \\
\text { sendiri) }\end{array}$ & 0 & 0 & & \\
\hline
\end{tabular}

Pada keseluruhan jawaban siswa mengenai proses siklus air kondensasi didapatkan hasil bahwa hampir seluruh dari siswa menjawab benar secara ilmiah meskipun masih terdapat siswa ketika diberi pertanyaan mengenai soal pada angket tersebut dan siswa menjawab tidak tahu karena belum belajar.

Data konsepsi awal tentang presipitasi pada siklus air didapatkan dari 2 butir soal pertanyaan pada angket, yaitu pada pertanyaan nomor 5 dan 6 . Hasil dari jawaban angket siswa dipaparkan pada tabel 3. 
Tabel 3. Konsepsi Awal Siswa tentang Presipitasi

\begin{tabular}{cclccccc}
\hline No & Aspek yang Ditanyakan & Jawaban & Jml & \% & Jawaban Ilmiah & No. Soal \\
\hline 1 & Pengertian presipitasi & Transpirasi & 10 & 33 & Presipitasi & 5 \\
& & Presipitasi & 10 & 33 & & \\
& & Kondensasi & 4 & 13,3 & & \\
& & Evaporasi & 5 & 16,7 & & \\
& & -..jawaban & 1 & 3,3 & & \\
\multirow{5}{*}{2} & Proses presipitasi melalui & & & & \\
& gambar & Kondensasi & 5 & 16,7 & Presipitasi & 6 \\
& & Evaporasi & 4 & 13,3 & & \\
& & Presipitasi & 14 & 46,7 & & \\
& & Penguapan & 6 & 20 & & \\
& & ...(jawaban & 1 & 3,3 & & \\
& sendiri) & & & & \\
\hline
\end{tabular}

Hasil dari angket dan wawancara yang diperoleh dari nomor 5, ditemukan hampir setengah dari seluruh siswa menjawab jatuhnya air ke bumi sebagai hujan disebut presipitasi. Sedangkan pada nomor 6 Hasil yang diperoleh dari angket dan wawancara, ditemukan hampir setengah dari keseluruhan siswa menjawab presipitasi.

Data konsepsi awal tentang siklus air pendek pada tahapan siklus air didapatkan dari 2 butir soal pertanyaan pada angket, yaitu pada pertanyaan nomor 7 dan 8. Hasil dari jawaban angket siswa dipaparkan pada tabel 4 .

Tabel 4. Konsepsi Awal Siswa tentang Siklus Air Pendek

\begin{tabular}{|c|c|c|c|c|c|c|}
\hline No & Aspek yang Ditanyakan & Jawaban & Jml & $\%$ & Jawaban Ilmiah & No. Soal \\
\hline \multirow[t]{5}{*}{1} & Pengertian presipitasi & $\begin{array}{l}\text { Siklus air } \\
\text { pendek }\end{array}$ & 7 & 23,3 & Siklus air pendek & 7 \\
\hline & & $\begin{array}{l}\text { Siklus air } \\
\text { sedang }\end{array}$ & 7 & 23,3 & & \\
\hline & & $\begin{array}{l}\text { Siklus air } \\
\text { panjang }\end{array}$ & 2 & 6,7 & & \\
\hline & & $\begin{array}{l}\text { Siklus air } \\
\text { hujan }\end{array}$ & 13 & 46,7 & & \\
\hline & & $\begin{array}{l}\text {...(jawaban } \\
\text { sendiri) }\end{array}$ & 1 & 3,3 & & \\
\hline \multirow[t]{5}{*}{2} & Proses presipitasi melalui & Panjang & 8 & 26,6 & Pendek & 8 \\
\hline & gambar & Sedang & 4 & 13,3 & & \\
\hline & & Pendek & 13 & 43,3 & & \\
\hline & & Berulang & 4 & 13,3 & & \\
\hline & & $\begin{array}{l}\text {...(jawaban } \\
\text { sendiri) }\end{array}$ & 1 & 3,33 & & \\
\hline
\end{tabular}

Hasil jawaban angket siswa dari nomor 7 ditemukan hampir seluruh siswa menjawab siklus air hujan. Sedangkan pada nomor 8 ditemukan hampir seluruh siswa menjawab siklus air pendek.

Data konsepsi awal tentang siklus air sedang pada tahapan siklus air didapatkan dari 1 butir soal pertanyaan pada angket, yaitu pada pertanyaan nomor 9. Hasil dari jawaban angket siswa dipaparkan pada tabel 5. 
Tabel 5. Konsepsi Awal Siswa tentang Siklus Air Sedang

\begin{tabular}{|c|c|c|c|c|c|c|}
\hline No & Aspek yang Ditanyakan & Jawaban & Jml & $\%$ & Jawaban Ilmiah & No. Soal \\
\hline \multirow[t]{5}{*}{1} & Definisi siklus air sedang & $\begin{array}{l}\text { Proses } \\
\text { pengedaran } \\
\text { air turun di } \\
\text { laut }\end{array}$ & 14 & 46,7 & $\begin{array}{l}\text { Proses } \\
\text { pengedaran air } \\
\text { hujan yang turun } \\
\text { di daratan }\end{array}$ & 9 \\
\hline & & $\begin{array}{l}\text { Proses } \\
\text { pengedaran } \\
\text { air hujan } \\
\text { yang turun } \\
\text { di daratan }\end{array}$ & 12 & 43,3 & & \\
\hline & & $\begin{array}{l}\text { Proses } \\
\text { pengedaran } \\
\text { air jatuh ke } \\
\text { pegunungan } \\
\text { dan } \\
\text { menyerap } \\
\text { sebelum } \\
\text { menjadi mata } \\
\text { air }\end{array}$ & 3 & 10 & & \\
\hline & & $\begin{array}{l}\text { Proses } \\
\text { pengedaran } \\
\text { air dimana } \\
\text { uap air } \\
\text { mengalami } \\
\text { sublimasi }\end{array}$ & 0 & 0 & & \\
\hline & & $\begin{array}{l}\text {...(jawaban } \\
\text { sendiri) }\end{array}$ & 0 & 0 & & \\
\hline
\end{tabular}

Hasil dari penggalian konsepsi awal siswa tentang siklus air sedang ditemukan hampir separuh dari siswa menjawab siklus sedang itu pengedaran air yang turun pada peraira laut dan separuh dari siswa menjawab siklus air sedang itu pengedaran air hujan yang turun diatas permukaan bumi atau daratan.

Data konsepsi awal tentang siklus air panjang pada tahapan siklus air didapatkan dari 1 butir soal pertanyaan pada angket, yaitu pada pertanyaan nomor 10. Hasil dari jawaban angket siswa dipaparkan pada tabel 6 .

Tabel 6. Konsepsi Awal Siswa tentang Siklus Air Panjang

\begin{tabular}{cclcclc}
\hline No & Aspek yang Ditanyakan & Jawaban & Jml & \% & Jawaban Ilmiah & No. Soal \\
\hline 1 & Definisi siklus air panjang & Sedang & 3 & 10 & Panjang & 10 \\
& & Pendek & 0 & 0 & & \\
& & Panjang & 13 & 43,3 & & \\
& & Berulang & 12 & 40 & & \\
& & ...(jawaban & 0 & 0 & & \\
& Sendiri) & & & & \\
\hline
\end{tabular}

Hasil penggalian konsepsi awal siswa ditemukan hampir setengah dari siswa menjawab siklus air yang melalui tahapan mulai dari matahari menyinari bumi kemudian terjadi penguapan setah itu uap air mengalami sublimasi yang menyebabkan hujan ini disebut juga dengan siklus air panjang. 


\section{Simpulan}

Berdasarkan paparan data, temuan penelitian dan pembahasan yang telah dijabarkan sebelumnya, dapat dikemukakan kesimpulan sebagai berikut. (1) Konsepsi awal siswa terhadap proses hujan presipitasi yaitu pada bagian pengertian presipitasi, sebagian besar (67\%) memiliki konsepsi yang belum benar secara ilmiah ditemukan kesalahan terbesar siswa bahwa jatuhnya titik air ke bumi sebagai hujan itu disebut juga dengan transpirasi, (2) Konsepsi awal yang belum benar secara ilmiah paling banyak ditemukan pada jenis siklus air pendek yaitu hampir seluruh siswa (77\%) memiliki konsepsi awal yang belum benar secara ilmiah pada pengertian air pendek. Sedangkan pada proses siklus air pendek yang disajikan dalam gambar sebagian besar dari siswa memiliki konsepsi awal yang belum benar secara ilmiah, (3) Konsepsi awal siswa yang sudah benar secara ilmiah paling banyak ditemukan pada proses siklus air hujan evaporasi yaitu sebagian besar siswa (62\%) sudah memiliki konsepsi awal yang benar pada pengertian dari evaporasi atau penguapan dan sebagian besar dari siswa (60\%) sudah memiliki konsepsi awal yang benar secara ilmah tentang penyebab terjadinya evaporasi, (4) Konsepsi awal yang dimiliki siswa beragam dan tidak sama antara siswa satu dengan lainnya.

\section{Daftar Rujukan}

Hasanuddin, I. M. (2020). Pengetahuan Awal (prior knowledge): konsep dan implikasi dalam pembelajaran. EDISI: Jurnal Edukasi dan Sains, 2(2), 217-232.

Maemunawati, S. \& Muhammad, A. (2020). Peran Guru, Orangtua, Metode dan Media Pembelajaran: Strategi KBM di Masa Pandemi Covid-19. Banten: 3M Media Karya Serang.

Maulidya, S. R., \& Saputri, N. I. (2016). Mengapa Siswa Menghadapi Kesulitan dalam Belajar Matematika? Seminar Nasional Matematika dan Pendidikan Matematika UNY, 475-480.

Sujana, A. \& Kurnia, A. (2018). Pembelajaran Sains di Sekolah Dasar. Sumedang: UPI Sumedang Press.

Yudrik, J. (2015). Psikologi Perkembangan. Jakarta: Kencana. 